of training for those who are going to lead the programme in their home, including training for the managers to ensure it is well-led throughout the home, and then there are inhouse sessions for the individual homes to inform the whole team.

Results Currently there have been 16 homes recruited and trained to implement the Namaste Care Programme. All homes are at varying degrees of the implementation phase due to individual circumstances of that home. There are some homes that have very early results that are showing both qualitative and quantitative improvements in individuals' quality of life within their homes.

Conclusion We plan to review progress and publish results in March 2019.

\section{P-90 COMPARING PLACE OF DEATH OF PATIENTS SUPPORTED BY A SPECIALIST DEMENTIA SERVICE WITH NATIONAL DATA}

Sarah Priestley, Nuno Santos Lopes, Karen Mclvor. Royal Trinity Hospice, London, UK

\subsection{6/bmjspcare-2018-hospiceabs.115}

Background Dementia is the leading cause of death in the United Kingdom. Specialists in end of life care need to adapt to the needs of the increasingly older population which it serves. There is pressure on the National Health Service to provide cost effective, evidence-based care and to avoid unnecessary hospital admissions at the end of life. Recent national data shows that $32 \%$ of people with dementia die in hospital.

Aim To understand whether a hospice-led dementia team influences the number of hospital and home deaths in patients with dementia, compared with national data.

Methods A sample of patients who were supported by the specialist dementia team was selected retrospectively, to include all deaths between 1st June 2017 and 31st May 2018 $(n=39)$. We have counted all the deaths using Excel spreadsheet and separated deaths into four different categories: Home, Hospice, Hospital and Care Home.

Results There were 39 deaths of patients with dementia that received support from the Dementia Nurse Specialists.

\begin{tabular}{lccc}
$\begin{array}{l}\text { Abstract P-90 Table } 1 \\
\text { place of death data }\end{array}$ & Comparing Hospice Team with national \\
\hline $\begin{array}{l}\text { Place of } \\
\text { Death }\end{array}$ & $\begin{array}{c}\text { Number of deaths under } \\
\text { Dementia Team }\end{array}$ & $\begin{array}{c}\text { Percentage deaths under } \\
\text { Dementia Team }\end{array}$ & $\begin{array}{c}\text { England } \\
(\mathbf{2 0 1 2}- \\
\text { 14) }\end{array}$ \\
\hline Home & 19 & $49 \%$ & $8 \%$ \\
Care Home & 10 & $26 \%$ & $58 \%$ \\
Hospital & 7 & $18 \%$ & $32 \%$ \\
Hospice & 3 & $8 \%$ & $1 \%$ \\
\hline
\end{tabular}

Of these patients $69 \%$ of them achieved their preferred place of death.

Conclusion Receiving care from a hospice-based dementia nurse specialist team was associated with a much higher home death rate of $49 \%$, compared with the national figure of $8 \%$. It was also associated with a lower rate of hospital deaths $18 \%$ compared with $32 \%$.

\section{P-91 DEMENTIA CARER SUPPORT IN A HOSPICE - AUDIT AGAINST NICE GUIDANCE}

Marie-Claire Rooney, Margaret Clifford, Deborah Pegram, Attia Rehman, May Slivnik. St Joseph's Hospice, London, UK

\subsection{6/bmjspcare-2018-hospiceabs.116}

Background Much research has been conducted on the psychological implications of caring for family members with dementia (Watson, Tatangelo, McCabe, 2018). Support for carers may enhance the quality of care they provide and may reduce their distress (Abreu, Rodrigues, Sequeira et al, 2018). The National Institute for Health and Care Excellence (NICE) identifies assessment of carers' psychological needs and interventions to address these needs as important aspects of care provision for people with dementia (NICE, 2010).

Aims To evaluate our hospice's compliance with NICE Guidelines on support for carers of dementia patients.

Methods We examined the Integrated Palliative Outcomes Scales (iPOS) of all patients on our inpatient and community caseloads with a primary diagnosis of 'dementia' to assess how many had a score completed for the 'family anxiety' question and whether those who had severe or overwhelming anxiety had an offer of formal support.

Results Only 33\% of patients had an iPOS 'family anxiety' score completed. Of those with severe or overwhelming anxiety, 78\% were offered formal support.

Conclusion Evaluation of our practice shows that while we offered support to the majority of those who were identified as needing it, only a third of carers' needs were assessed at the outset using the iPOS. It may be that a higher proportion of carers had their needs assessed informally as part of MultiDisciplinary Team assessments and this was not captured in the audit data. To ensure carers' needs are assessed consistently, we plan to educate staff regarding the importance of completing the 'family anxiety' question on iPOS, and are going on to complete a more detailed carers' assessment and offer of formal support if needed

\section{P-92 GETTING IT RIGHT: HEPATIC FAILURE AND PALLIATIVE CARE}

'Lucy Bemand-Qureshi, ${ }^{2}$ Leena Patel, ${ }^{2}$ Corinna Midgley. ${ }^{1}$ Royal Free Hospital, London, UK; ${ }^{2}$ Saint Francis Hospice, Havering-atte-Bower, UK

10.1136/bmjspcare-2018-hospiceabs.117

Background National work identifies that people with liver disease are less likely to receive palliative care, more likely to die in hospital, less likely to be satisfied with co-ordination of care (Kendrick, 2013) and more likely to be young, deprived and socially isolated (Public Health England - Liver disease profiles). Locally palliative care and hepatology services were struggling to connect.

Aims To audit local hospice and hospital outcomes for people with liver disease against the 2013 NHS report 'Getting it right: improving end of life care for liver disease' (Kendrick, 2013).

Methods Review of notes of people with a primary diagnosis of liver disease referred to the local hospice services or hospital palliative care team, 2015-2017. 
Results 16 hospice and 50 hospital referrals made.

Age: Hospice: 41-83 years, mean 62.5. Hospital: 3980 years, mean 54 .

$63 \%$ of hospice referrals came from the hospital palliative care team; none from hepatologists. $40 \%$ of hospital PCT referrals came from nurses; 20\% from hepatologists.

Reasons: Multiple for each service. Symptom control was most frequently cited: $81 \%$ vs. $60 \%$ respectively.

Prognostic indicators: $44 \%$ of hospice referrals included no indicators. No hospital referrals included indicators.

Mean duration of care: 39 days under hospice services, four days under the hospital PCT.

Outcomes Hospice referrals: 16 deaths; 5 (31\%) in hospital (though four were never discharged). Hospital referrals: 8/10 $(80 \%)$ with alcoholic liver disease vs $8 / 19$ (42\%) other diagnosis died in hospital. 36 hospital patients achieved advance care planning.

Conclusions Our audit identified high symptom burden, low hepatology input and late referrals to specialist palliative care. It has helped us to understand each others caseloads/roles, the burden of the disease for patients and the need to collaborate for advance care planning. We will now be using/sharing prognostic indicators (Gold Standards Framework) for and at referral, and are working together for a dedicated advanced disease hepatology clinic or CNS service.

\section{P-93 MAPPING OF END OF LIFE RECOGNITION AND PALLIATIVE CARE PROVISION IN COPD}

${ }^{1}$ Frances Hakkak, ${ }^{2}$ Helen Ward, ${ }^{3}$ Andrew Woods. ${ }^{1}$ Compton Care, Wolverhampton, UK; ${ }^{2}$ Royal Wolverhampton NHS Trust, Wolverhampton, UK; ${ }^{3}$ GraphnetHealth Ltd, Milton Keynes, UK

\subsection{6/bmjspcare-2018-hospiceabs.118}

Background COPD kills almost 30000 people per year in the UK (British Lung Foundation, 2016). NICE guidelines suggest patients with end-stage COPD should have access to palliative care services (NICE, 2010). Gold Standards Framework prognostic indicators assist clinicians to identify patients who are approaching end of life at an earlier stage enabling appropriate interventions to take place (2011). These patients are more likely to receive well-coordinated and high-quality care.

Aims The aim of our study was to map the number of QoFregistered COPD patients in our locality, the frequency of COPD specific GSF indicators, the number included on primary palliative care registers ( $\geq 2$ GSF prognostic indicators) and the number reviewed by palliative care.

Methods A multidisciplinary group with membership from Clinical Commissioning Group, acute trust, hospice and community team oversaw the project. Data was collated from across all health care sites enabling us to confirm the number and type of GSF prognostic indicators for each patient and healthcare activity including palliative care reviews.

Results In March 2016 there were 4999 COPD patients; 52\% were male with an average age of 69.2 years. $24.6 \%$ of patients $(n=1232)$ had $\geq 1$ GSF prognostic indicator. The most common indicator was MRC dyspnoea score of $4 / 5$ $(58.4 \%)$, followed by body mass index $<20$ (22.9\%). Of the 254 patients with $\geq 2$ GSF prognostic indicators $15.4 \%$ were on the GP palliative care register. $20.1 \%$ of the 254 patients had been reviewed by the palliative care team.

Conclusion GSF prognostic indicators in COPD are prevalent with breathlessness being the most common. Only a small proportion of appropriate patients were included on the palliative care register (15.4\%) with more being seen by specialist palliative care teams than on the registers. Further work is needed to ensure effective communication and education is provided across the whole healthcare system to identify patients earlier who are approaching end of life.

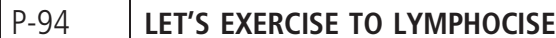

Elise Kendall, Joy Porter, Patricia Holmes. Mountbatten Hospice, Isle of Wight, UK

10.1136/bmjspcare-2018-hospiceabs.119

Introduction There is emerging evidence supporting the benefits of exercise in helping to relieve the symptoms of lymphoedema by stimulating lymphatic flow and improving circulation, which then reduces swelling. It also increases flexibility and joint range of motion, strengthens muscles and improves posture. A weekly group exercise programme was set up, tailored specifically to meet the needs of those with lymphoedema on the hospice caseload.

Aims of the project To improve physical symptoms and quality of life for people with lymphoedema. To provide a relaxed and sociable environment to exercise in. To give peer support and an opportunity to spend time with others who have similar problems. To empower the participants to continue to selfmanage their condition, continuing with exercise at home and/ or in their local communities.

Approach used All patients attend an initial full physiotherapy and lymphoedema assessment which involves measurement of the affected $\operatorname{limb}(\mathrm{s})$, outcome measures of a five times sit to stand test and a quality of life questionnaire. Patients attend a weekly exercise class for eight weeks. The sessions begin with a warm up aimed at improving lymphatic drainage, followed by an individually tailored circuit type exercise session and end with a gentle cool down. At the end of the eight sessions outcome measures are repeated.

Outcomes A clear link between exercise and reduction in limb size, improved mobility and general wellbeing has been observed with improvements in all outcome measures. Other benefits of the programme include improved confidence and self-esteem, increased take up of exercise and change in garment type required.

Conclusion Exercise can have far reaching benefits to those living with lymphoedema; significantly improving strength, stamina and overall quality of life.

\section{P-95 BACK TO THE FUTURE: A SERVICE EVALUATION}

Angela Ives, Stacy Pugh. Compton Care, Wolverhampton, UK

10.1136/bmjspcare-2018-hospiceabs. 120

Compton Lymphoedema Care was established 21 years ago to support palliative and curative patients with a lifelong condition. It has been identified in the business plan that there's a need to review lymphoedema referrals in terms of numbers and quality to provide optimum and timely patient care. If lymphoedema is recognised early, physical complications can be minimised (Cooper, 2010).

Aims To improve the referral process for our stakeholders. To improve stakeholders' knowledge of lymphoedema. To 